\title{
COMMENTARY
}

\section{Positioning of patients with acute respiratory distress syndrome: combining prone and upright makes sense}

\author{
Jean-Christophe M Richard ${ }^{1 *}$ and Jean-Claude Lefebvre1,2 \\ See related research by Robak et al., http://ccforum.com/content/15/5/R230
}

\begin{abstract}
Positional strategies have been proposed for mechanically ventilated patients with acute respiratory distress syndrome. Despite different physiological mechanisms involved, oxygenation improvement has been demonstrated with both prone and upright positions. In the previous issue of Critical Care, Robak and colleagues reported the first study evaluating the short-term effects of combining prone and upright positioning. The combined positioning enhanced the response rate in terms of oxygenation. Other benefits, such as a reduction in ventilator-associated pneumonia and better enteral feeding tolerance, can potentially be expected.
\end{abstract}

Prone positioning is widely used to improve oxygenation of patients with acute respiratory distress syndrome (ARDS). In the previous issue, Robak and colleagues report the short-term impact of combining two positioning strategies, prone and upright positioning [1]. Although randomized controlled trials failed to demonstrate an overall mortality benefit with the prone position, a trend toward better survival was observed for patients with severe ARDS [2-5]. The use of the prone position is supported by a strong physiological rationale and a significant improvement of the oxygenation status is observed in roughly $70 \%$ of ARDS patients [6]. Several mechanisms have been advocated to explain this effect, but the most determinant probably involves better aeration and recruitment of the vertebra-diaphragmatic

*Correspondence: jcm.richard@hcuge.ch

'Hôpitaux universitaires de Genève, Rue Gabrielle-Perret-Gentil 4, 1211, Geneva 14, Switzerland

Full list of author information is available at the end of the article lung regions, as a consequence of the reduction in ventral chest wall $(\mathrm{CW})$ compliance due to direct compression on the bed [6,7]. The CW compliance then becomes more uniform and the ventilation more evenly distributed. Interestingly, either high baseline CW compliance or a greater reduction in its magnitude with the prone position were associated with oxygenation improvement [6].

Upright positioning has also been associated with oxygenation improvement in ARDS patients and was proposed as an alternative to the prone position [8,9]. We previously demonstrated, in a group of 16 ARDS patients submitted to upright positioning, a significant increase in the $\mathrm{PaO}_{2} / \mathrm{FiO}_{2}$ ratio $(94 \pm 33$ versus $142 \pm 49 \mathrm{mmHg}$, $P<0.0032)$ in comparison to the baseline value obtained with the supine position [9]. With respect to the responders, the significant increase in the measured endexpiratory lung volume, coupled with the change in chord compliance after switching to upright positioning, suggested a time-dependent lung recruitment phenomenon. Based on physiological studies, one can postulate that the oxygenation improvement is mainly due to a lung volume redistribution induced by reduced ventral $\mathrm{CW}$ compliance during prone positioning, while an increase of the lung volume (recruitment) appears more significant during upright positioning. Because of their complementary mechanisms of action, combining prone and upright positioning can make sense in severe ARDS patients. Likewise, it has already been shown that the combination of prone positioning with an adjunctive technique to increase lung volume, the recruitment maneuvers, has additive positive effects on oxygenation [10].

In the physiological study of Roback and colleagues [1], the upright-prone position was achieved by raising the head of the bed and lowering the foot end to obtain an angle of at least $20^{\circ}$ (reverse Trendelenburg). This was associated with a significant improvement in the $\mathrm{PaO}_{2} /$ $\mathrm{FiO}_{2}$ ratio, without any short-term adverse events. The 
proportion of responders increased by combining the prone with the upright position, which is particularly relevant since the prone position is usually discontinued in the absence of oxygenation improvement.

This study was the first to specifically investigate the effect on gas exchange of combining prone and upright positioning. Unfortunately, the study design precluded conclusions about the precise physiological mechanisms involved. Measurements of the lung volumes would have been useful to better document the alteration of respiratory mechanics related to both prone and upright positioning. Regarding the redistribution of aerated lung regions, directly assessing the regional changes could have added to our current understanding. Since computed tomography (CT) scanning cannot be done during upright positioning, alternative techniques, such as electrical impedance tomography, may have permitted a better delineation of the importance of ventilation redistribution from non-dependent toward dependent parts of the lung with the upright-prone position.

Beyond the impact on oxygenation, other beneficial effects can theoretically be expected from upright-prone positioning. Although the level of evidence is weak, both prone and upright positions have been associated with a decrease of ventilator-associated pneumonia $[4,11,12]$. An additive effect of these two strategies is plausible, but the pathophysiology of ventilator-associated pneumonia is complex and one should be prudent before making such an assumption. Furthermore, head elevation of patients ventilated in the prone position was shown to improve the tolerance of enteral feeding [13].

In summary, the use of prone and upright positioning should not be considered as opposing and mutually exclusive strategies, but more as complementary ones. Even if the level of evidence is debatable, combining prone and upright positioning seems to enhance the response rate in terms of oxygenation. Whenever the prone position is used, combining it with the upright position should be considered to improve oxygenation further and limit lung derecruitment. This strategy is easy to implement at no additional cost and with a low risk of major complications. Specific policies should be implemented to encourage caregivers to avoid as much as possible a strictly supine position. Future studies should aim at determining to what extent the addition of the upright position during, and perhaps also between, prone sessions can promote the maintenance of beneficial effects.

Abbreviations

ARDS, acute respiratory distress syndrome; $C W$, chest wall.
Competing interests

The authors declare that they have no competing interests.

\section{Author details}

'Hôpitaux universitaires de Genève, Rue Gabrielle-Perret-Gentil 4, 1211, Geneva 14, Switzerland. Intensive Care Unit, Centre Hospitalier Universitaire de Québec, Québec, Canada.

Published: 15 December 2011

\section{References}

1. Robak O, Schellongowski P, Bojic A, Laczika K, Locker GJ, Staudinger T: Shortterm effects of combining upright and prone positions in patients with ARDS: a prospective randomized study. Crit Care 2011, 15:R230.

2. Sud S, Sud M, Friedrich JO, Adhikari NK: Effect of mechanical ventilation in the prone position on clinical outcomes in patients with acute hypoxemic respiratory failure: a systematic review and meta-analysis. CMAJ 2008, 178:1153-1161.

3. Kopterides P, Siempos, II, Armaganidis A: Prone positioning in hypoxemic respiratory failure: meta-analysis of randomized controlled trials. J Crit Care 2009, 24:89-100.

4. Sud S, Friedrich JO, Taccone P, Polli F, Adhikari NK, Latini R, Pesenti A, Guérin C, Mancebo J, Curley MA, Fernandez R, Chan MC, Beuret P, Voggenreiter G, Sud M, Tognoni G, Gattinoni L: Prone ventilation reduces mortality in patients with acute respiratory failure and severe hypoxemia: systematic review and meta-analysis. Intensive Care Med 2010, 36:585-599.

5. Abroug F, Ouanes-Besbes $L$, Elatrous $S$, Brochard $L$ : The effect of prone positioning in acute respiratory distress syndrome or acute lung injury: a meta-analysis. Areas of uncertainty and recommendations for research. Intensive Care Med 2008, 34:1002-1011.

6. Pelosi P, Tubiolo D, Mascheroni D, Vicardi P, Crotti S, Valenza F, Gattinoni L: Effects of the prone position on respiratory mechanics and gas exchange during acute lung injury. Am J Respir Crit Care Med 1998, 157:387-393.

7. Chiumello D, Cressoni M, Racagni M, Landi L, Li Bassi G, Polli F, Carlesso E, Gattinoni L: Effects of thoraco-pelvic supports during prone position in patients with acute lung injury/acute respiratory distress syndrome: a physiological study. Crit Care 2006, 10:R87.

8. Hoste EA, Roosens CD, Bracke S, Decruyenaere JM, Benoit DD, Vandewoude $\mathrm{KH}$, Colardyn FA: Acute effects of upright position on gas exchange in patients with acute respiratory distress syndrome. I Intensive Care Med 2005, 20:43-49.

9. Richard JC, Maggiore SM, Mancebo J, Lemaire F, Jonson B, Brochard L: Effects of vertical positioning on gas exchange and lung volumes in acute respiratory distress syndrome. Intensive Care Med 2006, 32:1623-1626.

10. Rival G, Patry C, Floret N, Navellou JC, Belle E, Capellier G: Prone position and recruitment manoeuvre: the combined effect improves oxygenation. Crit Care 2011, 15:R125.

11. Drakulovic MB, Torres A, Bauer TT, Nicolas JM, Nogue S, Ferrer M: Supine body position as a risk factor for nosocomial pneumonia in mechanically ventilated patients: a randomised trial. Lancet 1999, 354:1851-1858.

12. Alexiou VG, lerodiakonou V, Dimopoulos G, Falagas ME: Impact of patient position on the incidence of ventilator-associated pneumonia: a metaanalysis of randomized controlled trials. J Crit Care 2009, 24:515-522.

13. Reignier J, Dimet J, Martin-Lefevre L, Bontemps F, Fiancette M, Clementi E, Lebert C, Renard B: Before-after study of a standardized ICU protocol for early enteral feeding in patients turned in the prone position. Clin Nutr 2010, 29:210-216.

doi:10.1186/cc10560

Cite this article as: Richard JCM, Lefebvre JC: Positioning of patients with acute respiratory distress syndrome: combining prone and upright makes sense. Critical Care 2011, 15:1019. 